Tetrahedron Letters

journal homepage: www.elsevier.com

\title{
Isomerization of coencapsulated molecules
}

\author{
Kang-da Zhang ${ }^{\mathrm{b}}$, and $*$ Julius Rebek, Jr. ${ }^{\mathrm{a}, \mathrm{b}}$ \\ ${ }^{a}$ Department of Chemistry, Fudan University, 220 Handan Road, Shanghai, 200433 China. \\ ${ }^{b}$ Skaggs Institute for Chemical Biology, The Scripps Research Institute, and Department of Chemistry, 10550 North Torrey Pines Road, La Jolla, CA 92037
}

\section{ARTICLE INFO}

\section{Article history:}

Received

Received in revised form

Accepted

Available online

\section{ABSTRACT}

A cylindrical capsule host, held together by hydrogen bonds, takes up guests with polar solvent molecules. The arrangements and motions of molecules in the host's space are deduced from NMR experiments.

2009 Elsevier Ltd. All rights reserved.

\section{Keywords:}

Encapsulation

Cavitands

Rearrangement

Social Isomers

Folded Alkanes

We recently developed a deep cavitand 1a (Figure 1) with pyridinium "feet" that shows good solubility in aqueous media. The hydrogen bond donors and acceptors on the "rim" are selfcomplementary, and were introduced with cavitands $\mathbf{1 b}$ and $\mathbf{1 c}$ by de Mendoza more than a decade ago. ${ }^{1}$ Cavitands $\mathbf{1 b}$ and $\mathbf{1 c}$ form dimeric encapsulation complexes in organic solvents when suitable guests are present. $^{2}$
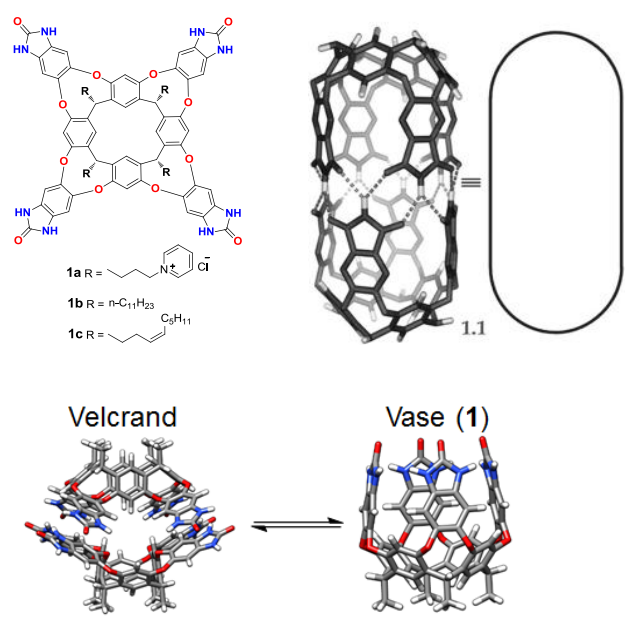

Figure 1 Cavitand 1a and capsule $\mathbf{1 . 1}$ are water-soluble over a range of temperatures and $\mathrm{pH}$. The resting conformations are velcrands, which revert to complexes of the vase in the presence of suitable guests (the hydrophilic "feet" have been truncated in the modeled structures).
In water, the resting state of $\mathbf{1 a}$ is the velcrand, a dimer of the self-complementary "kite" conformation. ${ }^{3}$ Sonication with short alkanes such as octane leads to stoichiometric 1:1 complexes of the vase conformation. The cavitand also binds molecules with polar headgroups such as ibuprofen, and the octanoyl function of the gastric peptide ghrelin. ${ }^{4}$ Surprisingly, 1 a formed the capsule 1.1 in water $\left(\mathrm{D}_{2} \mathrm{O}\right)$ when lengthy, hydrophobic guests were present. Despite the competitive nature of the solvent, the capsule forms through hydrogen bonding. ${ }^{5}$ We have now found other solvents that support encapsulation and we report their coencapsulation behaviour here.

The cavitand 1a is water-soluble as the chloride anion but conversion to the $\mathrm{PF}_{6}{ }^{-}$counterion rendered it soluble in polar organic solvents such as acetonitrile and acetone. In these media, complexes are formed when sizable guests are present. Unexpectedly, these solvents do not dominate the cavitand or capsule's interiors, despite their overwhelming concentration advantages. In acetonitrile, the capsules filled only with solvent show a single resonance at $-1.3 \mathrm{ppm}(\Delta \delta=-3.2 \mathrm{ppm})$ as revealed by spiking the deuterated solvent with $10 \% \mathrm{CH}_{3} \mathrm{CN}$ (Figure 2, trace a). These narrow solvent molecules can tumble freely inside and slip past each other to exchange positions rapidly on the NMR timescale. Accordingly, this signal represents the weighted average of two guests at the ends of the capsule where the upfield shift is greatest $(\Delta \delta=-4.8 \mathrm{ppm})$ and one guest at the middle where $\Delta \delta$ is -1.8 ppm. $^{8}$ When $p$-ethyl-toluene is present in $\mathrm{CD}_{3} \mathrm{CN}$, coencapsulation occurs generating social isomers ${ }^{1} \mathbf{2}$ and 3 (Figure 2, trace b). Two sets of signals for the guests appear in the upfield NMR window, indicating slow exchange (on the NMR timescale) of positions inside the capsule. The guests are 

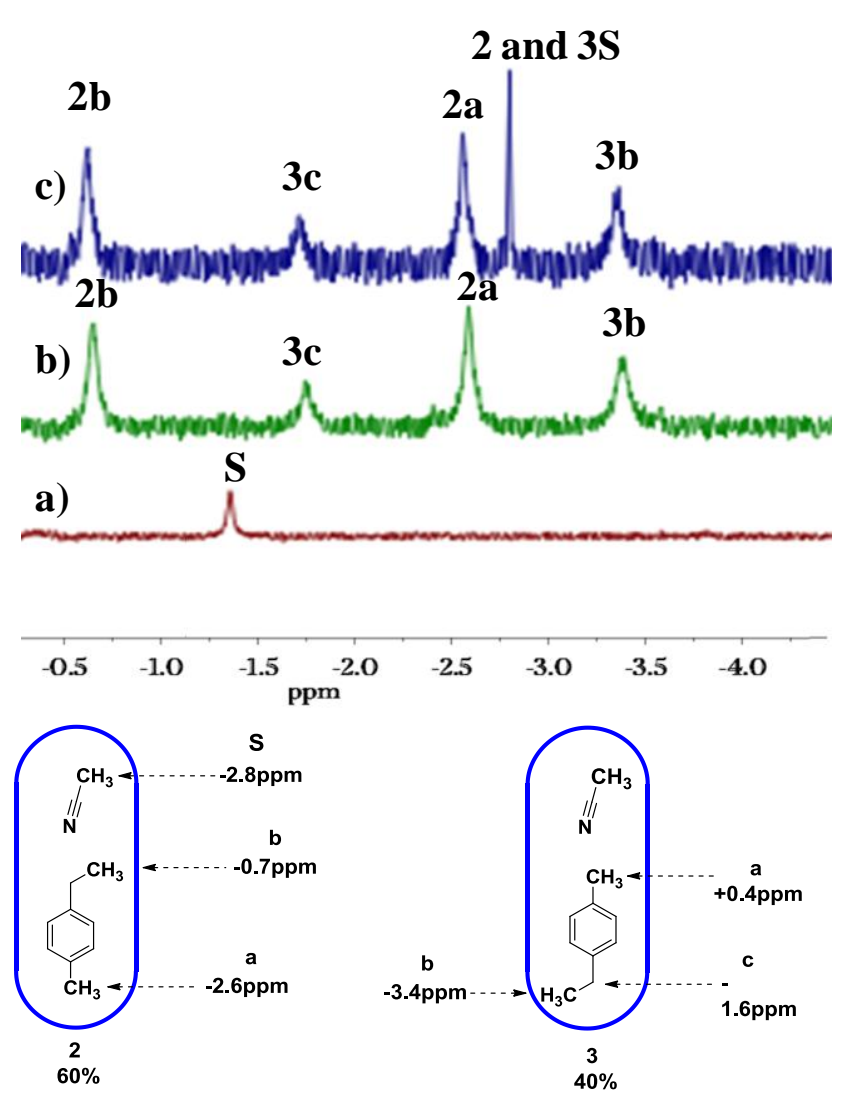

Figure 2: Top: Upfield regions of NMR spectra of guests in 1. $\mathrm{PF}_{6^{-}}(600 \mathrm{MHz}, 298 \mathrm{~K})$ in $\mathrm{CD}_{3} \mathrm{CN} / \mathrm{CH}_{3} \mathrm{CN}$ (90:10) solvent. (a) $\mathrm{CD}_{3} \mathrm{CN} / \mathrm{CH}_{3} \mathrm{CN}$ alone; (b) $p$-ethyl toluene with $\mathrm{CD}_{3} \mathrm{CN}$; (c) p-ethyl-toluene in $\mathrm{CD}_{3} \mathrm{CN} / \mathrm{CH}_{3} \mathrm{CN}$. Bottom: Cartoons of coencapsulated guests of trace (c).

too large to slide past each other and the $p$-disubstituted benzene is too long to tumble freely while inside the capsule. The concentrations reflect their relative energies: the methyl group ( $v s$ the ethyl group) prefers the tapered end of the space inside by a factor of about 1.5 , corresponding to a $\Delta \Delta \mathrm{G}$ of $0.24 \mathrm{kcal} / \mathrm{mol}$. The spectra with coencapsulated $\mathrm{CD}_{3} \mathrm{CN}$ and that spiked with $10 \% \mathrm{CH}_{3} \mathrm{CN}$ are shown in Figure 2 traces $\mathrm{b}$ and $\mathrm{c}$, respectively. In the latter the $\mathrm{CH}_{3} \mathrm{CN}$ at the end of the capsule can be observed at $-2.8 \mathrm{ppm}(\Delta \delta=-4.7 \mathrm{ppm})$.

The coencapsulated acetonitrile is readily replaced by chloroform. Addition of a small amount of $\mathrm{CHCl}_{3}$ to the $\mathrm{CD}_{3} \mathrm{CN}$ solution of $p$-ethyl-toluene gave the social isomers $\mathbf{4}$ and $\mathbf{5}$ (Figure 3). However, the same ratio (1.5:1) between social isomers of $\mathrm{CD}_{3} \mathrm{CN}$ and $\mathrm{CHCl}_{3}$ suggests that the disposition of the large guest in the capsule is the determining factor, rather than specific interactions between the two guests. In a related capsule held together by looser, bifurcated hydrogen bonds, ${ }^{6}$ the corresponding ratio of $\mathbf{4 : 5}$ in $\mathrm{CHCl}_{3}$ solvent ${ }^{7}$ was $4: 1$.

Coencapsulation spectra of $\mathrm{CD}_{3} \mathrm{CN} / \mathrm{CH}_{3} \mathrm{CN}$ with $n$-alkanes are shown in Figure 4. Two molecules of pentane (trace a) and hexane (trace b) were bound, as were single molecules of decane (trace f) and undecane (trace g). The shorter guests are compressed and tumble rapidly in the space, while the longer guests are in extended conformations that do not permit tumbling. All of these arrangements showed a symmetrically filled capsule assembly, with solvent excluded from the space.
Guests of intermediate length showed different behavior. Heptane (trace c) and octane (trace d) gave spectra that showed broadened peaks for the alkanes and a signal at $-2.8 \mathrm{ppm}$ for $\mathrm{CH}_{3} \mathrm{CN}$ inclusion at the ends of the capsule. The signals of the capsule, however, showed it to be symmetrical - at least on the NMR timescale. In other words, the two ends of the capsules showed an averaged magnetic environment, consistent with the rapid movement (rearrangement) of the $\mathrm{CH}_{3} \mathrm{CN}$ from one end of the space to the other. The methyl groups of heptane and octane are shifted downfield, (-1.3 and $-1.0 \mathrm{ppm}$, respectively) and indicate that they are not at the tapered ends of the capsule, but near its center: these alkanes are folded. With nonane as the guest, the signals are sharper and all 9 alkane signals are resolved (trace e). Uniquely, the two ends of the capsule are in different magnetic environments. There is also a $10^{\text {th }}$ signal at $-0.4 \mathrm{ppm}$. It represents the $\mathrm{CH}_{3} \mathrm{CN}$ exchanging on the NMR timescale between the capsule $(-2.8 \mathrm{ppm})$ and the bulk solvent $(+1.9 \mathrm{ppm})$. Such in/out exchange has precedent in a related capsule with gaseous coguests. ${ }^{9}$ The arrangements and motions of coencapsulated heptane and nonane are interpreted in the cartoons of Figure 4.

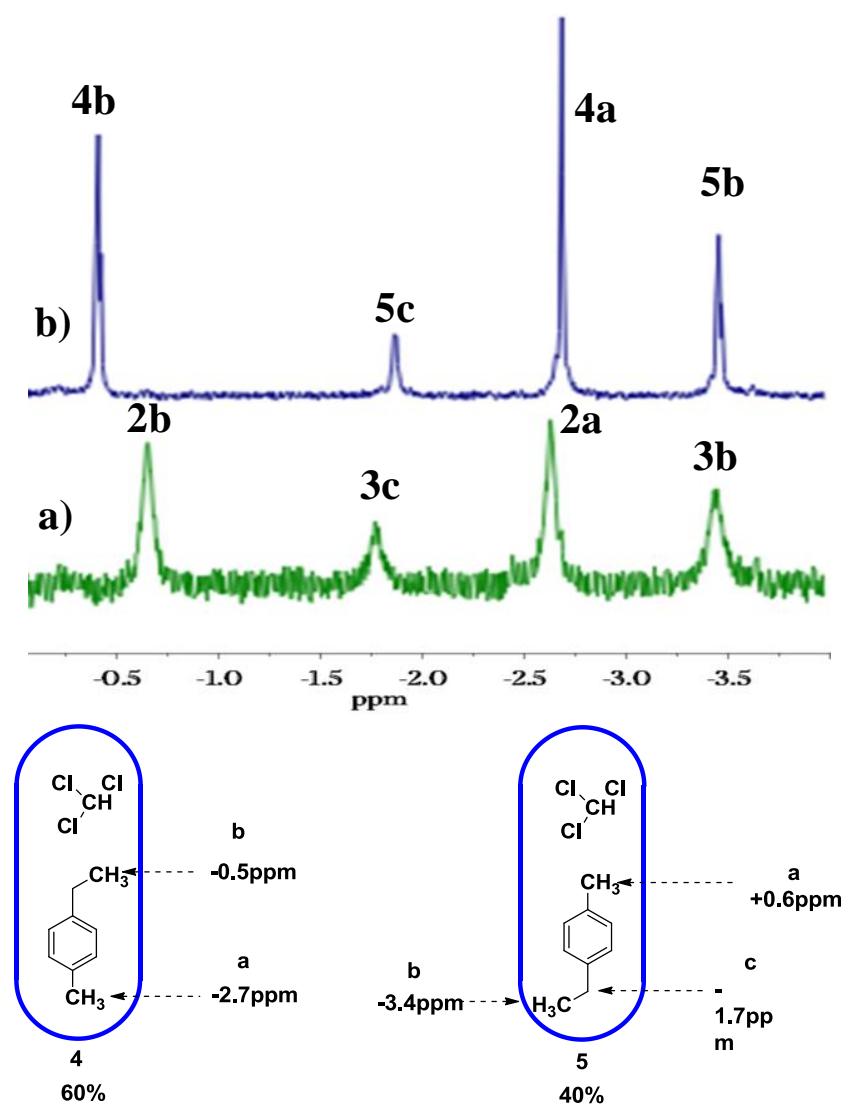

Figure 3: Top: Upfield regions of NMR spectra of guests in 1. $\mathrm{PF}_{6^{-}}(600 \mathrm{MHz}, 298 \mathrm{~K})$ in $\mathrm{CD}_{3} \mathrm{CN}$ solvent. (a) $\mathrm{CD}_{3} \mathrm{CN}$ with p-ethyl toluene; (b) After addition of $\mathrm{CHCl}_{3}$ to (b). Bottom: Cartoons of social isomers $\mathbf{4}$ and $\mathbf{5}$ of $\mathrm{CHCl}_{3}$ coencapsulated with $p$-ethyl toluene in $\mathrm{CD}_{3} \mathrm{CN}$ solvent.

What causes the break in the behavior of octane vs nonane? The answer is not obvious. We propose that the nonane/ $\mathrm{CH}_{3} \mathrm{CN}$ combination may exert enough pressure on the capsule to weaken the hydrogen bonds of the assembly to allow the exchange of $\mathrm{MeCN}$ to proceed more rapidly. At the same time, the compressed, possibly coiled ${ }^{10}$ nonane may "clog" the center of 
the capsule and prevent the back and forth slippage of $\mathrm{CH}_{3} \mathrm{CN}$ within. Whatever the reason(s), the favorable solubility of the $\mathrm{PF}_{6}{ }^{-}$salt permits its use in a number of solvents or mixed media. Recent work by Costa $^{11}$ has also shown that related cavitands will bind small guests in $\mathrm{MeCN} / \mathrm{D}_{2} \mathrm{O}$ mixtures. The present container molecules have significant advantages over earlier water-soluble cavitands that have ionizable groups and operate at limited $\mathrm{pH}$ ranges. ${ }^{12,13}$ Moreover, the molecular weights are considerably lower than that of covalent, neutral water-soluble cavitands. ${ }^{14, \text { is }}$ The folded conformations of the guests suggest applications in cyclization processes and we will report these in the sequel.

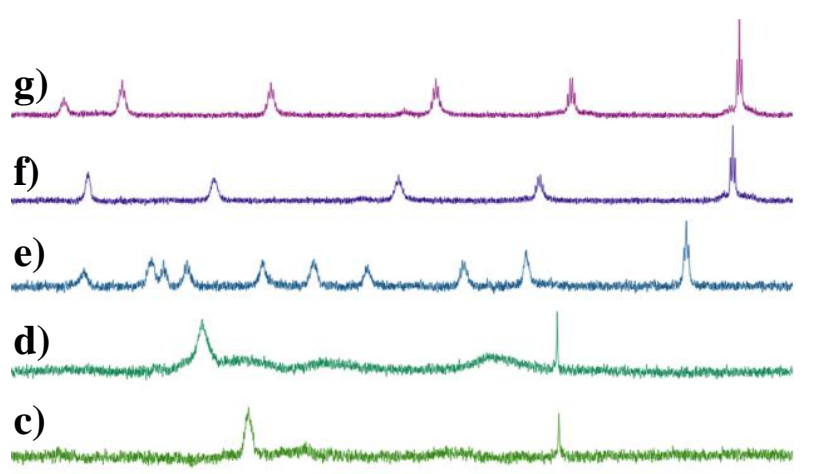

b)

a)
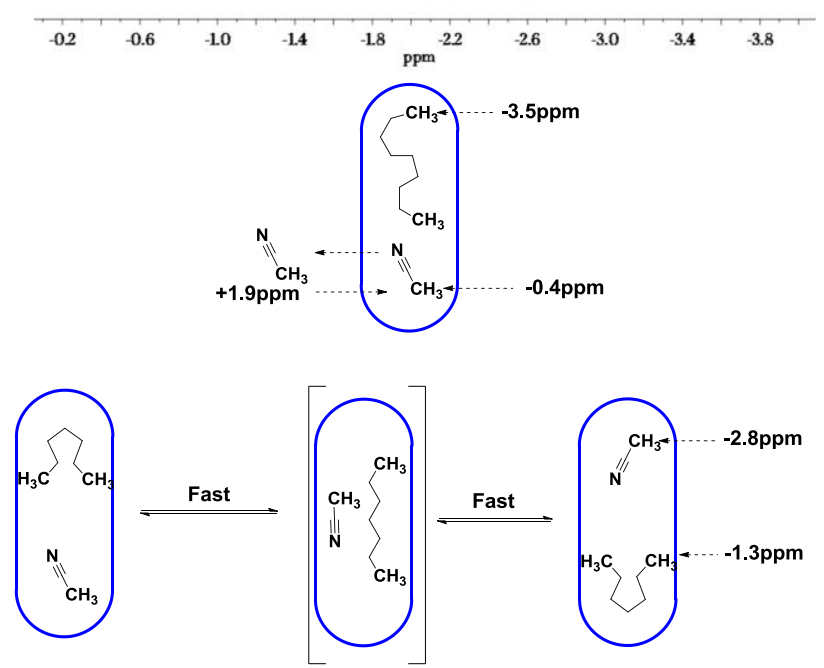

Figure 4: Top: Upfield regions of NMR spectra of n-alkane guests in $1 . \mathrm{PF}_{6^{-}}(600 \mathrm{MHz}, 298 \mathrm{~K})$ in $\mathrm{CD}_{3} \mathrm{CN} / \mathrm{CH}_{3} \mathrm{CN}(90: 10)$ solvent. (a) pentane; (b) hexane; (c) heptane; (d) octane; (e) nonane; (f) decane; (g) undecane. The $\mathrm{CH}_{3} \mathrm{CN}$ signals are labeled. Bottom: $\mathrm{CH}_{3} \mathrm{CN}$ coencapsulated with heptane slips rapidly from end to end, but with nonane the exchange is with bulk solvent.

\section{Acknowledgments}

We are grateful to the National Science Foundation $(\mathrm{CH}$ 1213415) for support.

\section{References and notes}

1. $\quad$ Ebbing, M. H. K.; Valpuesta, J. M.; Prados, P.; de Mendoza, J.; Proc. Natl. Acad. Sci. U.S.A. 2002, 99, 4962-4966.

2. Choi, H. J.; Park, Cho, C. S.; Koh, K.; Paek, K. Org. Lett. 2004, 6, 4431-4433.

3. Cram, D. J.; Choi, H. J.; Bryant, J. A.; Knobler, C. B. J. Am. Chem. Soc. 1992, 114, 7748-7765.

4. Zhang, K-D.; Ajami, D.; Gavette, J. V.; Rebek, Jr., J. Chem Commun. 2014, 50, 4895-4897.

5. Zhang, K-D.; Ajami, D.; Rebek, Jr., J. J. Am Chem. Soc. 2013, 135, 18064-18066.

6. Shivanyuk, A.; Rebek, Jr., J. J. Am. Chem. Soc. 2002, 124, 1207412075 .

7. Shivanyuk, A.; Rebek, Jr., J. Angew. Chemie, Int. Ed. 2003, 42, 684-686.

8. Ajami, D.; Iwasawa, T.; Rebek, Jr., J. Proc. Natl. Acad. Sci. U.S.A. 2006, 103, 8934-8936. Schleyer, P. v. R.; Maerker, C.; Dransfeld, A.; Jiao, H; Hommes, N. J. R. v. E. J. Am. Chem. Soc., 1996, 118, 6317-6318

9. Ajami, D.; Schramm, M. P.; Rebek, Jr., J. Tetrahedron 2009, 65, 7208-7212.

10. Scarso, A.; Trembleau, L.; Rebek, Jr., J. J. Am. Chem. Soc. 2004, 126, 13512-13518.

11. Soberats, B.; Sanna, E.; Martorell, G.; Rotger, C.; Costa, A. Org. Lett. 2014, 16, 840-843.

12. Trembleau, L; Rebek, Jr., J. Science 2003, 301, 1219-1220.

13. Liu, S.; Gibb, B.C. Chem. Commun. 2008, 3709-3716.

14. Giles, M.D.; Liu, S.; Emanuel, R. L.; Gibb, B. C.; Grayson, M. J. Am. Chem. Soc. 2008, 130, 14430-14431.

15. Lledo, A.; Rebek, Jr., J. Chem. Commun. 2010, 46, 8630-86342.

\section{Supplementary Material}

Supplementary material that may be helpful in the review process should be prepared and provided as a separate electronic file. That file can then be transformed into PDF format and submitted along with the manuscript and graphic files to the appropriate editorial office.

\section{Click here to remove instruction text...}




\section{Graphical Abstract}

To create your abstract, type over the instructions in the template box below.

Fonts or abstract dimensions should not be changed or altered.

\section{Isomerization of coencapsulated molecules}

Leave this area blank for abstract info.

Kang-Da Zhang and Julius Rebek, Jr.

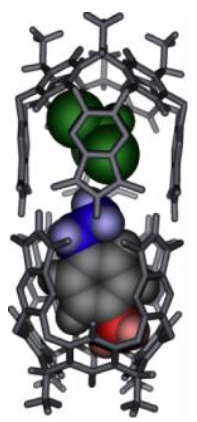

